\title{
REVIEW AND THE STATE OF THE ART PADA PERSIMPANGAN BERSINYAL DENGAN MODEL FUZZY LOGIC
}

\author{
Moch. Duddy Studyana \\ Staf Pengajar Jurusan Teknik Sipil Politeknik Negeri Bandung \\ Jl. Gegerkalong Hilir Ds. Ciwaruga Kotak Pos 1234 Bandung 40012 \\ Email: Study_lembur@yahoo.co.id
}

\begin{abstract}
ABSTRAK
Masalah klasik kondisi lalu-lintas perkotaan adalah sering timbulnya kemacetan (jam), antrian (queue), penurunan kapasitas simpang (drop capacity) dan waktu tunggu (delay time) yang lama saat melewati persimpangan. Keberhasilan dalam menangani suatu persimpangan akan menjadikan tolok ukur guna mengevaluasi kinerja simpang (intersection performance). Kenyataan yang terjadi dilapangan pengaturan sinyal lalu-lintas (traffic light) seringkali dilakukan dengan melibatkan berdasarkan variabel yang bersifat numerik atau kuantitatif, padahal variabel yang bersifat linguistik atau kualitatif sering diabaikan dan ada kecenderungan tidak pernah dipertimbangkan.
\end{abstract}

Ternyata penggunaan model fuzzy logic dapat memberikan kontribusi cukup besar dalam menangani kondisi persimpangan bersinyal, terutama pada penelitian ini dievaluasi terhadap waktu sinyal tetap (fixed time signal) dan simpang yang terisolasi (isolated intersection), karena dapat melibatkan analisa kombinasi variabel numerik dan linguistik.

Hasil review dan penelaahan secara the state of the art dari beberapa penelitian terdahulu, diharapkan akan menjadi terobosan baru untuk memberikan solusi terbaik bagi pengaturan sinyal lalu-lintas, khususnya simpang terisolasi yang berada di Indonesia.

Kata Kunci: fuzzy logic, review, the state of the art

\section{Pendahuluan}

Setiap kota besar seringkali mengalami terjadinya kemacetan dan kesemrawutan lalulintas pada hampir disetiap ruas serta persimpangan jalan, saat kondisi jam sibuk (peak hour) volume lalu-lintas bisa sangat tidak terkendali. Apalagi saat memasuki wilayah persimpangan, semua orang cenderung untuk saling mendahului dan segera meloloskan diri dari konflik kendaraan di persimpangan. Ini akan menjadi menarik untuk dilakukan analisa mengingat pada saat memasuki persimpangan sering terjadi konflik dan menyebabkan kendaraan tidak dapat bergerak karena saling mengunci (deadlock), maka yang akan terjadi dapat menyebabkan kemacetan (jam) dan antrian (queue) yang sangat panjang pada setiap lengan simpang, dan akan meningkatkan waktu tunggu (delay time) kendaraan yang cukup lama, juga akan menurunkan kapasitas simpang. Untuk mengatasi kemacetan dan kesemrawutan lalu-lintas tersebut diatas diperlukan suatu sistem penentuan sistem sinyal dan pengaturan lalu-lintas yang baik serta sangat berpengaruh pada kelancaran, kenyamanan, dan keselamatan bagi kendaraan saat melewati simpang jalan tersebut.

Sistem kontrol sinyal lalu-lintas dengan model fuzzy logic, menurut L.T. Wannige dan D.U.T Sonnadara (2008) adalah penggunaan kontrol sinyal dengan melibatkan input variabel seperti delay time, density, flow rate dan queue length melalui rata-rata arus kendaraan pada masingmasing lajur. Fuzzy logic adalah konsep berkesinambungan eksternal dengan kombinasi subyektif dan obyektif secara ilmu pengetahuan.

Pengertian dari pemakaian kontrol fuzzy logic dijelaskan oleh Mojtaba Salehi dkk (2014), adalah pemakaian linguistik "kata" misalnya: "jenuh", "kurang", "lama" yang sejalan dengan fikiran manusia. Pada umumnya bentuk

\section{PuEnSI REVIEW AND THE STATE OF THE ART PADA PERSIMPANGAN BERSINYAL DENGAN MODEL}


linguistik dalam transportasi sering tidak diketahui karena seringkali parameternya tidak jelas, seperti terjadi dua penafsiran berbeda (ambiguity), ketidakpastian (uncertainty), pengaruh lainnya (imprecision) atau subyektif (subjectivity). Ini biasanya akan terjadi bagi pengemudi, pejalan atau operator yang harus mengambil keputusan dilapangan, jadi ternyata informasi secara linguistik sangat berpengaruh secara subyektif karena menyangkut pengetahuan, persepsi atau mengambil keputusan.

Seperti kita ketahui teori yang digunakan untuk menyelesaikan masalah kemacetan lalu-lintas khususnya pada persimpangan diperlukan parameter arus kendaraan secara numerik atau kuantitatif, penanganan analisa kondisi tesebut dapat digunakan teori arus lalu-lintas (traffic flow theory). Ternyata kenyataan yang terjadi parameter lalu-lintas bisa bersifat kualitatif atau linguistik, misalnya arus kendaraan dikategorikan "padat", "normal" dan "sedikit", sehingga penanganannya perlu dilakukan peyelesaian menggunakan teori logika fuzzy (fuzzy logic theory).

Fuzzy logic systems dapat digunakan untuk analisa teknik transportasi, model kontrol sinyal lalu-lintas, pemakaian rute kendaraan, penjadwalan, analisa kecelakaan dan analisa pencegahannya, pertimbangan tingkat layanan, transportasi udara dan aplikasi transportasi sungai. Elemen dasar yang dipergunakan adalah adalah fuzzy set theory, fuzzy logic, fuzzy inference, fuzzifier, defuzzifier, termasuk konektifitas antara fuzzy logic dan probability theory, tentunya elemen tesebut dapat dipergunakan dalam analisa sinyal lalu-lintas persimpangan.

Bahasan penelitian berdasarkan data kualitatif telah dikemukakan oleh beberapa pakar transportasi dengan aplikasi teori fuzzy seperti, Abbas dan Salem (2012) mengemukakan gagasan penggunaan teori fuzzy guna mengontrol penambahan waktu hijau berdasarkan interval waktu kendaraan darurat (emergency car) saat melewati simpang, termasuk pengaturan waktu hijau (on/off) bagi pedestrian pada saat ambulance lewat. Gagasan lainnya oleh Pothai Vonglao (2007) mengaplikasikan teori fuzzy untuk menganalisis optimasi variabel lalu-lintas simpang dan menghitung panjang tiap waktu phase pada siklus (cycle time). Begitu halnya yang dikemukakan oleh Jarkko dan Marko (2000) teori fuzzy digunakan untuk analisis pertambahan waktu perpanjangan hijau untuk public transport. Sedangkan Alghamdi dan Eren (2013) teori fuzzy untuk menganalisis pengendalian kecepatan kendaraan dan masalah kemacetan simpang, ini hampir sama seperti yang dikemukakan oleh Peng dan Dong (2013) juga oleh Mojtaba Salehi dkk (2014).

Seringkali kondisi persimpangan bersinyal sudah tidak sesuai dengan harapan, seperti waktu menyala sinyal lalu-lintas untuk waktu hijau (green time) terlalu cepat atau terlalu lama, waktu merah (red time) sangat lama, antrian kendaraan terjadi disetiap lengan simpang, waktu tunggu (delay time) bagi kendaraan terlalu lama dan tidak ada prioritas bagi kendaraan umum (public transport) untuk segera melewati simpang, agar kinerja persimpangan bersinyal menjadi lebih baik maka perlu dilakukan optimalisasi untuk variabel tersebut.

\section{Kajian Pustaka}

Berdasarkan penelitian yang sudah dilakukan oleh Sonya (2008) dan Abbas (2012) terlihat dengan jelas bahwa kedua penelitian ini mempunyai kelebihan dalam hal pengukuran waktu hilang (loss time) secara mendetail.

Pengertiannya dengan pemakaian alat TTCD (Traffic Time Counter Display) dapat diukur berapa besar waktu hilang awal (start loss time) dan waktu hilang akhir (end loss time), ini sangat dibutuhkan dalam rangkaian waktu siklus (cycle time) agar kendaraan dapat meloloskan diri dari area simpang idealnya terjadi pengosongan untuk selanjutnya diisi oleh fase lengan berikutnya sehingga tidak terjadi konflik ditengah simpang.

Penentuan kedua loss time ini juga akan memberikan kontribusi untuk pengaturan waktu hijau aktual (actual green time) dan waktu hijau efektif (effective green time), harapannya dengan memberikan informasi awal kepada pengendara lamanya waktu menyala masingmasing warna akan membuat setiap orang lebih tertib dan waspada untuk berlalu-lintas, khususnya pada saat mendekati wilayah persimpangan dengan tidak melakukan pelanggaran lalu-lintas, sehingga tidak merugikan pengguna jalan lainnya. 
Penelitian Paothai Vonglao (2007) terlihat dengan jelas kelebihannya, yakni pada saat mengatasi kemacetan simpang ditinjau dari berbagai variabel pendukung artinya jumlah variabel untuk analisa cukup banyak malahan dengan melibatkan variabel kualitatif untuk memperkuat dasar analisis.

Sebagai gambaran saat melakukan perhitungan fase dapat digunakan berbagai analisa melalui teori arus (flow theory) juga dengan fuzzy theory dan ternyata ini menghasilkan panjang waktu masing-masing fase untuk arus terlindung (unopposite) dan terlawan (opposite) dalam suatu siklus lebih rinci dan akurat.

Kelebihan lainnya setiap input data yang diperoleh dilakukan pengujian dan validitas dengan berbagai teori statistika, sehingga ini akan menjamin kebenaran data secara empiris dan akhirnya diharapkan hasil analisa tingkat kesalahan (error) semakin kecil dengan demikian tingkat akurasi akan semakin meningkat.

Ternyata keberadaan kondisi suatu simpang juga perlu diperhatikan yakni dengan melihat lingkungan sekitarnya seperti wilayah perkantoran, bisnis, pendidikan atau pusat perbelanjaan dan ini merupakan fungsi integral dari pusat gravitasi atau pusat kegiatan (central of gravity).

Pendapat Jarkko N dan Marko M (2000) mempunyai kelebihan dalam hal pengaturan mobilitas kendaraan bis (public transport) ini jelas sangat bermanfaat sekali untuk memberikan pelayanan lebih bagi masyarakat pengguna angkutan umum sehingga waktu tempuh perjalanan akan lebih cepat, dan diharapkan akhirnya masyarakat akan lebih tertarik menggunakan moda bis untuk melakukan aktifitas sehari-hari.

Tentu ini akan berdampak pada pengurangan pemakaian kendaraan pribadi dan bisa mengurangi jumlah arus lalu-lintas yang bergerak di ruas atau simpang jalan dan secara tidak langsung berdampak pada berkurangnya tingkat kemacetan, juga dapat meminimasi antrian kendaraan simpang, memperpendek waktu tunggu rata-rata simpang dan meningkatkan kapasitas simpang.

Penggunaan model fuzzy logic dalam memberikan skala prioritas untuk public transport ternyata hasilnya sangat baik, karena melalui informasi numerik berdasarkan persepsi.

Penelitian Alghamdi dan Eren (2013) mempunyai kelebihan dalam mengontrol kecepatan kendaraan dan masalah kemacetan yang ditinjau dari sudut fuzzy logic, padahal dalam analisa pada umumnya seringkali hal ini dievaluasi berdasarkan perhitungan data kuantitatif karena kecepatan kendaraan dapat diukur secara numerik, baik itu untuk percepatan atau perlambatan kendaraan.

Tetapi disini dikupas melalui fuzzy sets dan fuzzy inference engine ternyata hasil yang diperoleh cukup baik dan bisa diandalkan untuk mewakili kondisi yang sebenarnya (existing).

Begitu halnya dengan penelitian yang dilakukan oleh Peng dkk (2013) dan Mojtaba Salehi dkk (2014), metoda fuzzy dijadikan alat pengukuran untuk antisipasi kemacetan simpang.

Termasuk penelitian oleh Cheng dkk (2013) dengan teori jaringan fuzzy dapat mengantisipasi kemacetan secara pola menyeluruh terhadap jaringan jalan sekitarnya dan ini sangat membantu sekali dalam mengurai suatu kemacetan pada titik tertentu atau wilayah rawan kemacetan.

Padahal biasanya untuk kondisi seperti ini dipergunakan analisa road network theory, ternyata ini juga merupakan terobosan terbaru pada era fuzzy logic, dan semoga ini dapat dikembangkan terus secara lebih lanjut pada masa yang akan datang.

Adapun rencana penelitian yang akan dilakukan diantaranya mempunyai kelebihan dibandingkan dengan penelitian sebelumnya adalah, seperti dalam rencana proses analisa melibatkan kombinasi input data varibel kuantitatif dengan kualitatif sehingga jumlah variabel yang akan diteliti menjadi cukup banyak, dan tentu diharapkan dengan jumlah variabel yang memadai akan betul-betul mewakili kondisi sebenarnya dilapangan. 
Penggunaan teori fuzzy logic dalam analisa dapat meningkatkan kinerja simpang dengan harapan nantinya akan diperoleh model optimasi simpang bersinyal yang cukup akurat.

Penelitian yang dilakukan oleh Sonya (2008) dan Abbas (2012), terlihat masih ada yang perlu ditambahkan misalnya dengan jumlah variabel disini hanya input 4 parameter yakni; arrival, queue, pedestrian dan emergency vehicle.

Padahal untuk mengukur atau mengevaluasi tingkat kemacetan suatu simpang bersinyal masih ada variabel lain yang memberikan kontribusi terhadap kondisi tersebut misalnya; delay time, phase, effective green time, cycle time, headway, speed,conflic area dan masih banyak lagi.

Tentu dengan bertambahnya jumlah variabel untuk proses perhitungan melalui teory fuzzy akan ada perbedaan misalnya untuk penyusunan metoda fuzzifiers, inference engine, dan defuzzifier.

Maka dengan kondisi tersebut pada proses rencana penelitian yang akan dilakukan, menjadi landasan dasar pemikiran untuk dilakukan pendalaman (expolored), dengan harapan hasil analisa yang dicapai akan menjadi lebih valid dan akurat.

Begitu halnya dengan penelitian yang dilakukan oleh Jarrko dan Marko (2000), juga oleh Alghamdi dan Eren (2013), Xiao dan Zhu (2013) serta Peng, Liang, Dong dan Liu (2013), Mojtaba Salehi dkk (2014), disini dibahas tentang skala prioritas untuk public transport yang akan melewati simpang.

Secara konsep dan tujuan sangat baik karena telah mendahulukan kepentingan kendaraan umum, tetapi yang perlu dicermati adalah pada saat penambahan waktu hijau atau waktu merah berubah menjadi hijau, ini harus diantisipasi pergerakan kendaraan dan pejalan kaki dari lengan simpang lainnya, karena perubahan tersebut sangat mendadak dan rawan terjadinya konflik.

Sehingga dapat menyebabkan kecelakaan mobil dengan motor atau mobil dengan pejalan kaki, mungkin karena pergerakan public transport tersebut frekuensinya jarang atau cenderung sangat kecil, sehingga pengendara lain sulit untuk menduga kapan kendaraan tersebut akan melintasi simpang.

Sedangkan penelitian lainnya membahas antisipasi kemacetan simpang dengan mengukur parameter variabel kecepatan, waktu hijau dan arus lalu-lintas dengan teori fuzzy, terlihat bahwa jumlah variabel yang dijadikan input data jumlahnya sedikit dan ini tentu sangat berpengaruh terhadap kinerja simpang bersinyal.

Pengertiannya ini perlu ada penambahan variabel misalnya perilaku pengendara, tingkat pelanggaran rambu persimpangan, sehingga teori yang dipergunakan akan lebih komplek dan dapat mempertegas obyek yang sebenarnya, sehingga mewakili kondisi eksisting.

Berdasarkan beberapa kekurangan tersebut maka rencana penelitian yang akan dilakukan, cenderung perlu dicari dan dilengkapi varibel yang berpengaruh pada persimpangan, dengan menggunakan teori fuzzy logic sebagai alat ukur kinerjanya.

\section{Metoda Penelitian}

Kajian yang dilakukan pada simpang bersinyal ini melalui pendekatan analisa seperti penelitian yang dikemukakan oleh Hideaki Y, Yo Ishzuka, Shigemichi (2006) membahas tentang rata-rata antrian dan penyimpangan waktu tunggu (delay time deviasi) yang berpengaruh terhadap signal, pendekatan dengan menggunakan varibel kedatangan (arrival), antrian (queue), waktu tunggu (delay time), arus lalu-lintas (traffic flow), rata-rata dan deviasi dengan menggunakan metoda Rantai Markov dan Optimum Pareto. Begitu halnya yang dikemukakan oleh Ning Zou (2007) mengupas kondisi simpang berdasarkan waktu sinyal tetap (fixed time signal), termasuk pengaruh time signal terhadap antrian juga pengaruh ramp signal terhadap antrian.

Adapun pendekatan dilakukan berdasarkan waktu hijau eksisting (existing green time),waktu hijau efektif (effective green time), waktu kedatangan (arrival), waktu merah eksisting (existing red time), waktu merah aktual (actual red time), antrian (queue), jarak antara (distance headway), waktu siklus (cycle time), 
kepadatan (density), waktu tunggu (delay time), arus lalu-lintas (traffic flow), fase (phase) dan pejalan kaki (pedestrian), sedangkan metoda yang digunakan adalah teori rantai markov.

Selanjutnya Chun Shao (2009) membahas simpang bersinyal melalui pendekatan waktu hijau eksisiting (existing green time), antrian (queue), jarak antara (distance headway), kecepatan (speed), waktu tunggu (delay time), arus lalu-lintas (traffic flow), fase (phase), sedangkan metoda yang digunakan dalam kondisi ini adalah model Wilcoxon dan Mann Whitney, teori Gabor dan Park, teori Pode.

Pembahasan teori fuzzy dilakukan oleh Pothai Vonglao (2007) pendekatannya hampir sama dengan bahasan yang dikemukakan oleh Ning Zou (2007), tetapi disini untuk metoda penelitiannya dikupas berbagai teori tentang Fuzzy seperti metoda fuzzy logic system, melalui uraian pembahasan dengan fuzzy rule base, fuzzy inference, fuzzifier dan defuzzifier, ternyata pemakaian metoda tersebut dalam analisa simpang bersinyal sangat memberikan warna tersendiri dalam penelitian.

Bahasan berikutnya masih melibatkan tentang teori fuzzy untuk analisis simpang dikemukakan oleh Alghamdi A dan Eren H (2013) melalui pendekatan variabel kecepatan (speed), arus lalu-lintas (traffic flow), percepatan (acceleration), perlambatan (deceleration), dan jarak antara (distance headway), dengan metoda fuzzy logic, melalui uraian fuzzy sets, fuzzy inference engine. Selanjutnya Xiao HX dan Zhu YF (2013) juga melakukan pendekatan melalui arus lalu-lintas (traffic flow), waktu hijau (green time), dan waktu merah (red time), digunakan metoda fuzzy control, dengan uraian rata-rata kendaraan (average vehicle), keputusan kontrol (control decision) dan dasar aturan fuzzy (fuzzy rule base).

Masih dengan cara yang sama pada tahun 2013 oleh Peng ML, Liang XR, Dong CJ dan Lin YY pendekatan dilakukan terhadap varibel arus lalulintas (traffic flow), waktu hijau (green time), waktu siklus (cycle time) dan kemacetan lalulintas (traffic congestion) dengan menggunakan metoda fuzzy logic, fuzzy inference engine. Pendekatan terakhir dilakukan oleh Mojtaba Salehi dkk (2014) terhadap simpang terisolasi melalui waktu tunda (delay time), perpanjangan waktu hijau, kontrol arus jenuh dan kecepatan kendaraan saat memasuki simpang dengan menggunakan metoda fuzzy system.

Adapun rencana penelitian simpang bersinyal ini dilakukan dengan metoda fuzzy logic theory, meliputi pendekatan kombinasi variabel lalulintas secara maksimum.

Guna memahami dan memudahkan proses penelitian ini perlu dilakukan langkah-langkah atau tahapan rencana secara berjenjang, agar dapat menghasilkan akurasi penelitian yang cukup valid dan dapat dipertanggung- jawabkan berdasarkan kaidah ilmiah.

Adapun diagram alur rencana penelitian dapat dilihat pada Gambar 1, yang dilakukan melalui tahapan proses sebagai berikut:

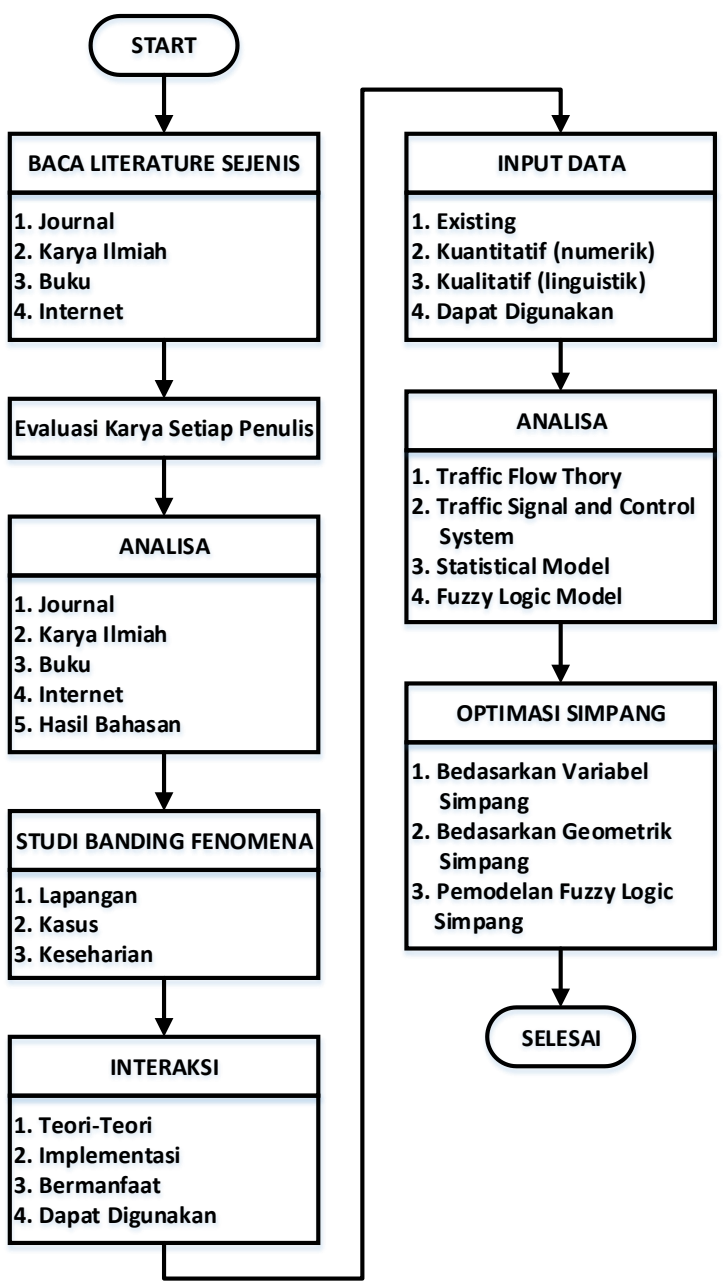

Gambar 1. Metodologi Penelitian

PuEERSI REVIEW AND THE STATE OF THE ART PADA PERSIMPANGAN BERSINYAL DENGAN MODEL 
Agar diperoleh the state of the art pada penelitian ini, maka diperlukan kumpulan data sekunder terutama penelitian yang pernah dilakukan oleh beberapa pakar Fuzzy Logic sebagai dasar acuan dan pembanding.

Selanjutnya mencari benang merah atau keterkaitan berdasarkan review dari setiap penelitian, guna mendapatkan konsep kebaruan yang akan menjadi dasar penelitian yang akan dilakukan.

Rekapitulasi dari masing-masing penelitian terdahulu diurutkan berdasarkan kronologi mulai dari tahun penemuan pertamakali sampai dengan tahun terakhir, dengan maksud agar

tidak terjadi pengulangan atau duplikasi penelitian.

\section{Evaluasi dan Hasil}

\section{IV.1 Review dan State of The Art}

Penelitian yang akan dilakukan menggunakan beberapa varibel lalu-lintas simpang bersinyal sebagai bahan input analisis optimasi persimpangan, dalam beberapa literatur sebelumnya pembahasan cenderung hanya menggunakan sebagian variabel yang ada, dan belum dibahas secara menyeluruh, untuk lebih jelasnya dapat dilihat pada tabel 1 .

Tabel 1. Review Jumlah Variabel Simpang Bersinyal

\begin{tabular}{|l|l|l|l|c|c|c|}
\hline No & \multicolumn{1}{|c|}{ Nama } & Tahun & \multicolumn{1}{|c}{ Hasil Pengamatan } & Jml Var & Fuzzy Simpang \\
\hline 1 & Ning Zou & 2007 & Panjang fase siklus & 16 & - & 4 \\
\hline 2 & Shun Shao & 2009 & Mengurai kemacetan simpang & 10 & - & 4 \\
\hline 3 & Lin-Li & 2010 & Estimasi Level of Service (LOS) & 11 & - & 4 \\
\hline 4 & Hua-Hua & 2010 & Mengurai antrian dan tundaan & 11 & - & 4 \\
\hline 5 & Burac C. & 2013 & Mengurangi tundaan, arus jenuh & 16 & - & $3 \& 4$ \\
\hline 6 & M. Alodat & 2013 & Optimalisasi waktu hijau & 7 & $*$ & 4 \\
\hline 7 & Jarkko & 2000 & Kontrol public transport & 28 & $*$ & 4 \\
\hline 8 & Pothai V & 2007 & Menghitung setiap fase siklus & 16 & $*$ & 4 \\
\hline 9 & M. Abbas & 2012 & Penambahan waktu hijau & 9 & $*$ & 4 \\
\hline 10 & Alghamdi & 2013 & Pengendalian kec kendaraan & 7 & $*$ & 4 \\
\hline 11 & Xiao & 2013 & Kontrol simpang tunggal & 4 & $*$ & 4 \\
\hline 12 & Peng & 2013 & Antisipasi kemacetan simpang & 9 & $*$ & 4 \\
\hline 13 & Mojtaba & 2014 & Tambah hijau \& kend darurat & 22 & $*$ & 3 \\
\hline
\end{tabular}

Sumber : Hasil Analisa

Keterangan: $*(\mathrm{Ya})$ dan $-($ Tidak $)$
Rencananya posisi penelitian ini akan menggunakan 8 variabel untuk data kuantitatif dan kualitatif terhadap berbagai kondisi simpang 4 sedangkan fokus penelitian adalah pengembangan optimasi dari simpang bersinyal dengan menggunakan metoda fuzzy logic, guna lebih jelasnya dapat dilihat pada tabel 2 berikut ini: 
Tabel 2. Matrik Penelitian Simpang Bersinyal Model Fuzzy

\begin{tabular}{|c|c|c|c|c|c|c|c|c|c|c|}
\hline NO & JUDUL & $\begin{array}{c}\text { ALAT } \\
\text { SURVEI }\end{array}$ & ANALISIS & HASIL RISET & $\begin{array}{c}\text { TEORI } \\
\text { DAN } \\
\text { ANALISIS }\end{array}$ & $\begin{array}{l}\text { KLASIFI } \\
\text { KASI } \\
\text { JURNAL }\end{array}$ & TAHUN & PENULIS & VARIABLE & $\begin{array}{c}\text { GEOME } \\
\text { TRIC }\end{array}$ \\
\hline 1 & $\begin{array}{lr}\text { Pengaruh } & \text { Traffic } \\
\text { Timer Counter } \\
\text { Display } & \text { (TTCD) } \\
\text { terhadap } & \text { Arus } \\
\text { Lalu-lintas } & \\
\text { Simpang } & \\
\text { Bersinyal } & \end{array}$ & $\begin{array}{l}\text { Box } \\
\text { TTCD }\end{array}$ & $\begin{array}{l}\text { TTCD Terhadap } \\
\text { Loss Time }\end{array}$ & $\begin{array}{l}\text { 1. Negatif TTCD tidak } \\
\text { berpengaruh (start } \\
\text { Loss Time) } \\
\text { 2. Positif } \\
\begin{array}{l}\text { berpengaruh } \\
\text { Loss Time) }\end{array}\end{array}$ & $\begin{array}{c}\text { MKJI, } \\
\text { Webster dan } \\
\text { Hobbs }\end{array}$ & $\begin{array}{l}\text { FSTPT } \\
\text { Journal }\end{array}$ & 2008 & $\begin{array}{c}\text { Sonya } \\
\text { Sulistyono }\end{array}$ & $\begin{array}{l}\text { Green Actual, } \\
\text { Loss Time (awal } \\
\text { \& akhir), Traffic } \\
\text { Flow }\end{array}$ & 4 \\
\hline 2 & $\begin{array}{l}\text { Mean and } \\
\text { Variance of } \\
\text { waiting Time and } \\
\text { Their } \\
\text { Optimization for } \\
\text { Alternating } \\
\text { Traffic Control } \\
\text { System }\end{array}$ & $\begin{array}{c}\text { Traffic } \\
\text { count }\end{array}$ & $\begin{array}{l}\text { Rata-rata antrian \& } \\
\text { devasi delay time } \\
\text { berpengaruh } \\
\text { terhadap signal }\end{array}$ & $\begin{array}{l}\text { 1. Positif rata2 panjang } \\
\text { antrian untuk kontrol } \\
\text { signal } \\
\text { 2. Positif deviasi } \\
\text { standar waktu } \\
\text { tunggu untuk kontrol } \\
\text { signal }\end{array}$ & $\begin{array}{c}\text { MAP, } \\
\text { Miller, } \\
\text { Newell, Dist } \\
\text { Poisson, } \\
\text { Rantai } \\
\text { Markov, } \\
\text { Optimum } \\
\text { Pareto }\end{array}$ & $\begin{array}{c}\text { Proquest } \\
\text { Journal }\end{array}$ & 2006 & $\begin{array}{l}\text { 1. Hideaki } \\
\text { Y } \\
\text { 2. Yo } \\
\text { Ishizuka } \\
\text { 3. Shigemac } \\
\text { hi S }\end{array}$ & $\begin{array}{l}\text { 1. Arrival } \\
\text { 2. Queue } \\
\text { 3. Delay } \\
\text { 4. Traffic Flow } \\
\text { 5. Rata-rata } \\
\quad \text { Deviasi }\end{array}$ & 2 \\
\hline 3 & $\begin{array}{l}\text { Fuzzy Logic } \\
\text { Based } \\
\text { Autonomous } \\
\text { Traffic Control } \\
\text { System }\end{array}$ & $\begin{array}{l}\text { Traffic } \\
\text { count } \\
\text { Camera }\end{array}$ & $\begin{array}{lr}\text { Algoritma } & \text { desain } \\
\text { Logic } & \text { Fuzzy } \\
\text { dipakai } & \text { untuk } \\
\text { sistem } & \text { kontrol } \\
\text { Simpang } & \text { Fuzzy } \\
\text { Expert } & \text { System } \\
\text { Fuzzifier, } & \text { De } \\
\text { Fuzzifier, } & \\
\text { Pengaturan } & \text { Phase, } \\
\text { Geometric, } & \text { Un } \\
\text { Opposite } & \end{array}$ & $\begin{array}{l}\text { 1. Simulasi Grafis } \\
\text { dalam System } \\
\text { (kurva) } \\
\text { 2. penambahan waktu } \\
\text { hijau berdasarkan } \\
\text { interval waktu } \\
\text { 3. (emergency car) } \\
\text { pada saat melewati } \\
\text { simpang } \\
\text { 4. Pengaturan waktu } \\
\text { hijau (on/off) bagi } \\
\text { pedestrian dan } \\
\text { lengan simpang } \\
\text { lainnya, saat } \\
\text { ambulance lewat }\end{array}$ & $\begin{array}{c}\text { COA } \\
\text { (Center of } \\
\text { Average), } \\
\text { Fuzzy Rule } \\
\text { Base, Fuzzy } \\
\text { Inference } \\
\text { Engine, } \\
\text { Fuzzy } \\
\text { Control }\end{array}$ & $\begin{array}{c}\text { Proquest } \\
\text { Journal }\end{array}$ & 2012 & $\begin{array}{c}\text { Muh.Abbas } \\
\text { M.Saleem K } \\
\text { Nasil Ali } \\
\text { Syed Fazil }\end{array}$ & $\begin{array}{l}\text { Arrival } \\
\text { Queue } \\
\text { Pedestrian } \\
\text { Emergency } \\
\text { Vehicle } \\
\text { Traffic Flow } \\
\text { Phase }\end{array}$ & 4 \\
\hline
\end{tabular}

PUEERI REVIEW AND THE STATE OF THE ART PADA PERSIMPANGAN BERSINYAL DENGAN MODEL 


\begin{tabular}{|c|c|c|c|c|c|c|c|c|c|c|}
\hline NO & JUDUL & $\begin{array}{c}\text { ALAT } \\
\text { SURVEI }\end{array}$ & ANALISIS & HASIL RISET & $\begin{array}{c}\text { TEORI } \\
\text { DAN } \\
\text { ANALISIS } \\
\end{array}$ & $\begin{array}{c}\text { KLASIFIK } \\
\text { ASI } \\
\text { JURNAL } \\
\end{array}$ & TAHUN & PENULIS & VARIABLE & $\begin{array}{c}\text { GEOME } \\
\text { TRIC }\end{array}$ \\
\hline 4 & $\begin{array}{l}\text { Self Organizing } \\
\text { Traffic Signals for } \\
\text { Arterial Control }\end{array}$ & Detector & $\begin{array}{l}\text { Mengontrol } \\
\text { efisiensi Traffic } \\
\text { Demand, Mengatur } \\
\text { variabel lalu-lintas, } \\
2 \text { phase not fixed } \\
\text { time + Queue } \\
\text { (dist.cycle length \& } \\
\text { average delay), 2 } \\
\text { phase fixed time + } \\
\text { Queue }\end{array}$ & $\begin{array}{l}\text { 1. Menurunkan waktu } \\
\text { delay untuk saturation } \\
\text { flow dan unsaturation } \\
\text { flow } \\
\text { 2. Menurunkan cycle } \\
\text { time }\end{array}$ & $\begin{array}{l}\text { Queue } \\
\text { Spillback, } \\
\text { Dist. } \\
\text { Poisson, } \\
\text { Signal } \\
\text { Control, } \\
\text { SCOOT, } \\
\text { SCATS, } \\
\text { PASSER, } \\
\text { MOTTION }\end{array}$ & Disertasi & 2013 & $\begin{array}{l}\text { Burac } \\
\text { Cesme }\end{array}$ & $\begin{array}{l}\text { Green Time } \\
\text { Existing, } \\
\text { Arrival, Loss } \\
\text { Time, Queue, } \\
\text { Headway, } \\
\text { Speed, Cycle } \\
\text { Time, Traffic } \\
\text { Flow, Delay, } \\
\text { Density, Phase, } \\
\text { Pedestrian. }\end{array}$ & $3 \& 4$ \\
\hline 5 & $\begin{array}{l}\text { Queuing Models } \\
\text { and Analysis of } \\
\text { Traffic Control }\end{array}$ & $\begin{array}{l}\text { Traffic } \\
\text { count }\end{array}$ & $\begin{array}{l}\text { Fixed Time Signal } \\
\text { Pengaruh Time } \\
\text { signal thd Queue } \\
\text { Pengaruh Ramp } \\
\text { signal thd Queue }\end{array}$ & $\begin{array}{l}\text { 1. Model Queue untuk } \\
\text { merubah Traffic light } \\
\text { 2. Model Queue untuk } \\
\text { Fixed Time Signal } \\
\text { 3. Model Queue untuk } \\
\text { menjalankan Signal } \\
\text { 4. Model Queue untuk } \\
\text { mengontrol } \\
\text { kelandaian (Ramp) }\end{array}$ & $\begin{array}{l}\text { HCM 85, } \\
\text { Clayton } \\
\text { Teori } \\
\text { (Webster, } \\
\text { Miller, } \\
\text { Matson, } \\
\text { Akcelic, } \\
\text { Newel, \& } \\
\text { Ousena) } \\
\text { Rantai } \\
\text { Markov }\end{array}$ & Disertasi & 2007 & Ning Zou & $\begin{array}{lr}\text { Green Time } \\
\text { Existing, Green } \\
\text { Time Effective, } \\
\text { Arrival, Red } \\
\text { Time Existing, } \\
\text { Red Time } \\
\text { Account, Queue, } \\
\text { Headway, Cycle } \\
\text { Time, Densitiy, } \\
\text { Phase, Delay, } \\
\text { Traffic Flow, } \\
\text { Pedestrian }\end{array}$ & 4 \\
\hline
\end{tabular}

Puntal REVIEW AND THE STATE OF THE ART PADA PERSIMPANGAN BERSINYAL DENGAN MODEL FUZZY LOGIC

Moch. Duddy Studyana 


\begin{tabular}{|c|c|c|c|c|c|c|c|c|c|c|}
\hline NO & JUDUL & $\begin{array}{c}\text { ALAT } \\
\text { SURVEI }\end{array}$ & ANALISIS & HASIL RISET & $\begin{array}{c}\text { TEORI DAN } \\
\text { ANALISIS }\end{array}$ & $\begin{array}{c}\text { KLASIFIK } \\
\text { ASI } \\
\text { JURNAL } \\
\end{array}$ & $\begin{array}{c}\text { TAHU } \\
\mathbf{N}\end{array}$ & PENULIS & VARIABLE & $\begin{array}{l}\text { GEOM } \\
\text { ETRIC }\end{array}$ \\
\hline 6 & $\begin{array}{l}\text { Adavtive Control } \\
\text { Strategy for } \\
\text { isolated } \\
\text { intersection and } \\
\text { Traffic Network }\end{array}$ & Detector & $\begin{array}{lr}\text { Pengaruh } & \text { Strategi } \\
\text { Signal } & \text { terhadap } \\
\text { simpang } & \text { teisolasi } \\
\text { dan Jaringan Lalu- } \\
\text { lintas }\end{array}$ & $\begin{array}{l}\text { 1. Pode: potensi } \\
\text { mengurai } \\
\text { kemacetan } \\
\text { simpang } \\
\text { 2. Gabnor: Analisis } \\
\text { Sensitivitas untuk } \\
\text { jalan arteri dan } \\
\text { pola jaringan grid }\end{array}$ & $\begin{array}{lr}\text { Teori } & \text { Pode, } \\
\text { Gabnor \& } & \text { Parks. } \\
\text { Model } & \text { Wilcoxon } \\
\text { dan } & \text { Mann } \\
\text { Whitney } & \end{array}$ & Disertasi & 2009 & Chun Sao & $\begin{array}{l}\text { Green Time } \\
\text { Existing } \\
\text { Queue Headway } \\
\text { Speed } \\
\text { Delay } \\
\text { Traffic Flow } \\
\text { Phase }\end{array}$ & 6 \\
\hline 7 & $\begin{array}{l}\text { Delay Model for } \\
\text { Signal Controller } \\
\text { Intersection }\end{array}$ & $\begin{array}{l}\text { Camera, } \\
\text { Traffic } \\
\text { count }\end{array}$ & $\begin{array}{l}\text { Optimasi waktu } \\
\text { signal pada simpang }\end{array}$ & $\begin{array}{l}\text { Estimasi Level of } \\
\text { Service (LOS) } \\
\text { simpang bersinyal }\end{array}$ & $\begin{array}{l}\text { Teori Optimasi, } \\
\text { Kontrol Phase, } \\
\text { Cycle Length, } \\
\text { Delay time, Model } \\
\text { (Wolshon, Tang, } \\
\text { Hsien, Rahim F, F. } \\
\text { Dion, Chen Shao, }\end{array}$ & Jurnal IEEE & 2010 & $\begin{array}{c}\text { Lin } \mathrm{Li} \\
\text { Jianmin } \mathrm{Xu} \\
\text { Sibo Huang } \\
\text { Kai Lu }\end{array}$ & $\begin{array}{l}\text { Traffic Flow, } \\
\text { Delay, Cycle } \\
\text { Time, Phase }\end{array}$ & 4 \\
\hline 8 & $\begin{array}{l}\text { Multi-objective } \\
\text { Optimization } \\
\text { Method of Fixed } \\
\text { Time Signal } \\
\text { Control of Isolated } \\
\text { Intersection }\end{array}$ & $\begin{array}{l}\text { Traffic } \\
\text { count, } \\
\text { Camera }\end{array}$ & $\begin{array}{l}\text { Model optimasi } \\
\text { variabel banyak } \\
\text { pada kontrol sinyal } \\
\text { waktu tetap simpang } \\
\text { tidak jenuh }\end{array}$ & $\begin{array}{l}\text { 1. Optimasi multi } \\
\text { obyek variabel } \\
\text { sangat ideal } \\
\text { mengukur } \\
\text { average vehicle } \\
\text { delay \& queue } \\
\text { length } \\
\text { 2. Efisien } \\
\text { mengurangi } \\
\text { average vehicle } \\
\text { delay }\end{array}$ & 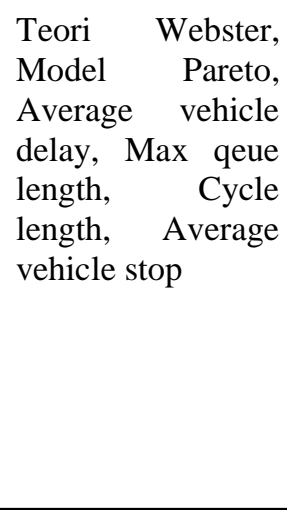 & Jurnal IEEE & 2010 & $\begin{array}{l}\text { Hu Hua } \\
\text { Gao Yunfeng } \\
\text { Yang } \\
\text { Xiaoguang }\end{array}$ & $\begin{array}{l}\text { Traffic } \quad \text { Flow } \\
\text { Total, Average } \\
\text { Delay, Average } \\
\text { Stop Frequency, } \\
\text { Average Queue } \\
\text { Length }\end{array}$ & 4 \\
\hline
\end{tabular}

PuEnSI REVIEW AND THE STATE OF THE ART PADA PERSIMPANGAN BERSINYAL DENGAN MODEL FUZZY LOGIC

Moch. Duddy Studyana 


\begin{tabular}{|c|c|c|c|c|c|c|c|c|c|c|}
\hline NO & JUDUL & $\begin{array}{c}\text { ALAT } \\
\text { SURVEI }\end{array}$ & ANALISIS & HASIL RISET & $\begin{array}{c}\text { TEORI DAN } \\
\text { ANALISIS }\end{array}$ & $\begin{array}{c}\text { KLASIFIK } \\
\text { ASI } \\
\text { JURNAL }\end{array}$ & $\begin{array}{c}\text { TAHU } \\
\mathbf{N}\end{array}$ & PENULIS & VARIABLE & $\begin{array}{l}\text { GEOM } \\
\text { ETRIC }\end{array}$ \\
\hline 9 & $\begin{array}{l}\text { The Solution of } \\
\text { Traffic Signal } \\
\text { Timing by using } \\
\text { Traffic Intensity } \\
\text { estimation and } \\
\text { Fuzzy Logic }\end{array}$ & $\begin{array}{l}\text { Traffic } \\
\text { count, } \\
\text { Dectecto } \\
\text { r, Camera }\end{array}$ & $\begin{array}{l}\text { Maximum Likelihood } \\
\text { Estimation } \\
\text { Bayes Inference } \\
\text { Estimation } \\
\text { Generate an } \\
\text { Exponential } \\
\text { Generate an Gamma } \\
\text { Generate an Bernoulli }\end{array}$ & $\begin{array}{l}\text { 1. Optimasi Varibel } \\
\text { lalu-lintas } \\
\text { 2. Menghitung } \\
\text { panjang tiap } \\
\text { waktu fase pada } \\
\text { siklus }\end{array}$ & $\begin{array}{c}\text { Fuzzy Logic } \\
\text { System, Fuzzy } \\
\text { Rule base, Fuzzy } \\
\text { Inference, } \\
\text { Fuzzifier, } \\
\text { Defuzzifier }\end{array}$ & Disertasi & 2007 & $\begin{array}{c}\text { Pothai } \\
\text { Vonglao }\end{array}$ & $\begin{array}{l}\text { Queue, Traffic } \\
\text { Flow, Phase, } \\
\text { Cycle Time, } \\
\text { Lost Time, } \\
\text { Delay Time, } \\
\text { Green Time, } \\
\text { Red Time }\end{array}$ & 4 \\
\hline 10 & $\begin{array}{l}\text { Fuzzy Public } \\
\text { Transport Priority } \\
\text { in Traffic Signal } \\
\text { Control }\end{array}$ & Detector & $\begin{array}{l}\text { Analisis } \\
\text { perpanjangan Green } \\
\text { Time }\end{array}$ & $\begin{array}{l}\text { Model Fuzzy } \\
\text { menghasilkan } \\
\text { keputusan dan } \\
\text { output yang sangat } \\
\text { baik untuk kontrol } \\
\text { Public Transport }\end{array}$ & $\begin{array}{lr}\text { Multi } & \text { Level } \\
\text { Fuzzy, } & \text { Fuzzy } \\
\text { Public } & \text { Transport, } \\
\text { Fuzzy } \quad \text { Logic, } \\
\text { Defuzzification } \\
\text { Method, Fuzzy } \\
\text { Similarity }\end{array}$ & $\begin{array}{l}\text { Academia } \\
\text { Edu }\end{array}$ & 2000 & $\begin{array}{l}\text { Jarkko N } \\
\text { Marko M }\end{array}$ & $\begin{array}{l}\text { Traffic Flow } \\
\text { Green Time } \\
\text { Red Time } \\
\text { Phase } \\
\text { Bus Car }\end{array}$ & 4 \\
\hline 11 & $\begin{array}{l}\text { Using Fuzzy Logic } \\
\text { to Control Vehicle } \\
\text { Velocity in Traffic } \\
\text { System }\end{array}$ & $\begin{array}{l}\text { Camera } \\
\text { Detector }\end{array}$ & $\begin{array}{l}\text { Sistem buka tutup } \\
\text { kendaraan }\end{array}$ & $\begin{array}{l}\text { Pengendalian } \\
\text { kecepatan } \\
\text { kendaraan dan } \\
\text { masalah kemacetan }\end{array}$ & $\begin{array}{l}\text { Fuzzy Logic, } \\
\text { Fuzzy Sets, Fuzzy } \\
\text { Inference Engine, } \\
\text { Acceleration, } \\
\text { Deceleration }\end{array}$ & Scopus & 2013 & $\begin{array}{l}\text { Alghamdi A } \\
\text { Eren } \mathrm{H}\end{array}$ & $\begin{array}{l}\text { Speed } \\
\text { Traffic Flow } \\
\text { Acceleration } \\
\text { Decelaration }\end{array}$ & 4 \\
\hline 12 & $\begin{array}{lr}\text { Traffic } & \text { Signal } \\
\text { Control } & \text { and } \\
\text { Simulation } & \text { of } \\
\text { Single } & \\
\text { Intersection Based } \\
\text { on Fuzzy Control }\end{array}$ & $\begin{array}{l}\text { Traffic } \\
\text { count } \\
\text { Camera }\end{array}$ & $\begin{array}{l}\text { Analisis simpang } \\
\text { dengan kontrol lalu- } \\
\text { lintas }\end{array}$ & $\begin{array}{l}\text { Kontrol Simpang } \\
\text { Tunggal } \\
\text { menghasilkan } \\
\text { simulasi sederhana } \\
\text { dengan Logic Fuzzy }\end{array}$ & $\begin{array}{l}\text { Traffic Flow, } \\
\text { Fuzzy Control, } \\
\text { Average Vehicle, } \\
\text { Fuzzy Rule Base, } \\
\text { Control Decision }\end{array}$ & Scopus & 2013 & $\begin{array}{l}\text { Xiao H X } \\
\text { Zhu Y F }\end{array}$ & $\begin{array}{l}\text { Traffic Flow } \\
\text { Green Time } \\
\text { Red Time }\end{array}$ & 4 \\
\hline
\end{tabular}

Putensl REVIEW AND THE STATE OF THE ART PADA PERSIMPANGAN BERSINYAL DENGAN MODEL FUZZY LOGIC

Moch. Duddy Studyana 


\begin{tabular}{|c|c|c|c|c|c|c|c|c|c|c|}
\hline No & JUDUL & $\begin{array}{c}\text { ALAT } \\
\text { SURVEI }\end{array}$ & ANALISIS & HASIL RISET & $\begin{array}{l}\text { TEORI DAN } \\
\text { ANALISIS }\end{array}$ & $\begin{array}{l}\text { KLASIFIKASI } \\
\text { JURNAL }\end{array}$ & TAHUN & PENULIS & VARIABLE & $\begin{array}{l}\text { GEOME } \\
\text { TRIC }\end{array}$ \\
\hline 13 & $\begin{array}{l}\text { Freeway Traffic } \\
\text { Congestion } \\
\text { Identification } \\
\text { Based on Fuzzy } \\
\text { Control }\end{array}$ & $\begin{array}{l}\text { Traffic } \\
\text { count } \\
\text { Camera }\end{array}$ & $\begin{array}{l}\text { Analisis Metode } \\
\text { Non Linear Metoda } \\
\text { identifikasi } \\
\text { kemacetan }\end{array}$ & $\begin{array}{l}\text { Perhitungan metoda } \\
\text { Logic Fuzzy sangat } \\
\text { akurat untuk } \\
\text { antisipasi } \\
\text { kemacetan }\end{array}$ & $\begin{array}{l}\text { Fuzzy Logic, } \\
\text { Fuzzy Inference } \\
\text { Engine, Phase, } \\
\text { Cycle Time, } \\
\text { Traffic } \\
\text { Congestion }\end{array}$ & Scopus & 2013 & $\begin{array}{c}\text { Peng M L } \\
\text { Liang X R } \\
\text { Dong C J } \\
\text { Lin Y Y }\end{array}$ & $\begin{array}{l}\text { Traffic Flow } \\
\text { Green Time }\end{array}$ & 4 \\
\hline 14 & $\begin{array}{lr}\text { Improve } & \text { and } \\
\text { Extension } & \text { Traffic } \\
\text { Light } & \text { at } \\
\text { Intersection } & \end{array}$ & $\begin{array}{l}\text { Traffic } \\
\text { count } \\
\text { Camera } \\
\text { Detector }\end{array}$ & $\begin{array}{l}\text { Mengontrol Green } \\
\text { dan fase } \\
\text { Perpanjangan } \\
\text { waktu Hijau } \\
\text { Menggunakan } \\
\text { fuzzy logic }\end{array}$ & $\begin{array}{l}\text { 1. Optimalisasi } \\
\text { kondisi simpang } \\
\text { bersinyal } \\
\text { 2. Mengurangi } \\
\text { kemacetan lalu- } \\
\text { lintas } \\
\text { 3. Prioritas Hijau } \\
\text { untuk setiap fase }\end{array}$ & $\begin{array}{l}\text { Fuzzy Logic, } \\
\text { Traffic Flow } \\
\text { Method, Fuzzy } \\
\text { Control }\end{array}$ & Scopus & 2013 & $\begin{array}{l}\text { M. Alodat } \\
\text { Iyas Alodat }\end{array}$ & $\begin{array}{l}\text { Green Time } \\
\text { Fase } \\
\text { Traffic Flow } \\
\text { Rate }\end{array}$ & 4 \\
\hline 15 & $\begin{array}{lrr}\text { TLCSBFL } & : \quad A \\
\text { Traffic } & \text { Light } \\
\text { Control } & \text { System } \\
\text { Based on } & \text { Fuzzy } \\
\text { Logic } & & \end{array}$ & $\begin{array}{l}\text { Camera } \\
\text { Detector }\end{array}$ & $\begin{array}{l}\text { Perluasan Green } \\
\text { Time } \\
\text { Mengontrol } \\
\text { kemacetan simpang } \\
\text { Simulasi kontrol } \\
\text { waktu tunggu, } \\
\text { jarak, } \\
\text { persimpangan, } \\
\text { kepadatan, } \\
\text { kecepatan }\end{array}$ & $\begin{array}{l}\text { Mengatasi } \\
\text { kemacetan, } \\
\text { kecelakaan, } \\
\text { kecepatan, arus } \\
\text { jenuh. } \\
\text { Mengurangi } \\
\text { kemacetan lalu- } \\
\text { lintas. } \\
\begin{array}{l}\text { Prioritas Hijau } \\
\text { untuk Emergency } \\
\text { vehicle }\end{array}\end{array}$ & $\begin{array}{l}\text { Fuzzy Logic, } \\
\text { Traffic Flow } \\
\text { Method, Fuzzy } \\
\text { logic Controller, } \\
\text { Fuzzy Sets, } \\
\text { Autonomous } \\
\text { System }\end{array}$ & IJUNESST & 2014 & $\begin{array}{c}\text { Mojtaba } \\
\text { Salehi } \\
\text { Iman } \\
\text { Sepahvand } \\
\text { M. Yarahmadi }\end{array}$ & $\begin{array}{l}\text { Traffic light } \\
\text { status } \\
\text { Emergency } \\
\text { Vehicle } \\
\text { Traffic Flow } \\
\text { Rate } \\
\text { Speed } \\
\text { Roadways }\end{array}$ & 3 \\
\hline
\end{tabular}

Putensl REVIEW AND THE STATE OF THE ART PADA PERSIMPANGAN BERSINYAL DENGAN MODEL FUZZY LOGIC

Moch. Duddy Studyana 
Adapun untuk aspek kebaruan dan manfaat yang dihasilkan, berdasarkan review dan state of the art dalam penelitian ini adalah :

1. Berdasarkan sudut keilmuan, dapat menjadi pengayaan khasanah ilmu pengetahuan tentang pemodelan optimasi transportasi khususnya kajian teknik lalu-lintas untuk simpang bersinyal.

2. Dari sisi metodologi, pendekatan yang digunakan pada variabel lalu-lintas untuk strategi pengembangan optimasi simpang bersinyal dengan menggunakan model fuzzy logic, diharapkan akan menghasilkan nilai yang lebih baik karena proses analisa menggunakan kombinasi data kuantitatif dan kualitatif sehingga secara obyektif mampu mencerminkan kondisi yang sebenarnya.

3. Bagi masyarakat atau individu, dapat dirasakan manfaat pengaturan persimpangan bersinyal secara terukur dan akurat tentu akan berdampak terhadap kelancaran berlalu-lintas, terhindar dari kemacetan yang berlarutlarut agar aktifitas masyarakat akan lebih produktif karena waktu perjalanan relatif cepat dan efisien, termasuk tingkat kecelakaan bagi pengguna kendaraan dapat ditekan seminimal mungkin melalui pengaturan fase simpang sehingga tidak terjadi konflik antar kendaraan ataupun dengan pejalan kaki.

4. Bagi pemerintah, tentunya ini akan menjadi masukan untuk kebijakan dalam mengontrol jaringan jalan khususnya persimpangan yang seringkali menjadi masalah kesemrawutan lalu-lintas terutama untuk kota-kota besar yang relatif jumlah kendaraannya cukup besar. Sehingga dengan terwujudnya lalu-lintas yang relatif aman, dan lancar akan menjadikan sebuah kota yang nyaman untuk dikunjungi oleh wisatawan domestik ataupun internasional.

Agar lebih mudah memahami rencana penelitian yang akan dilakukan, terutama untuk melihat posisi penelitian maka disusun dalam Gambar 2 berikut ini:

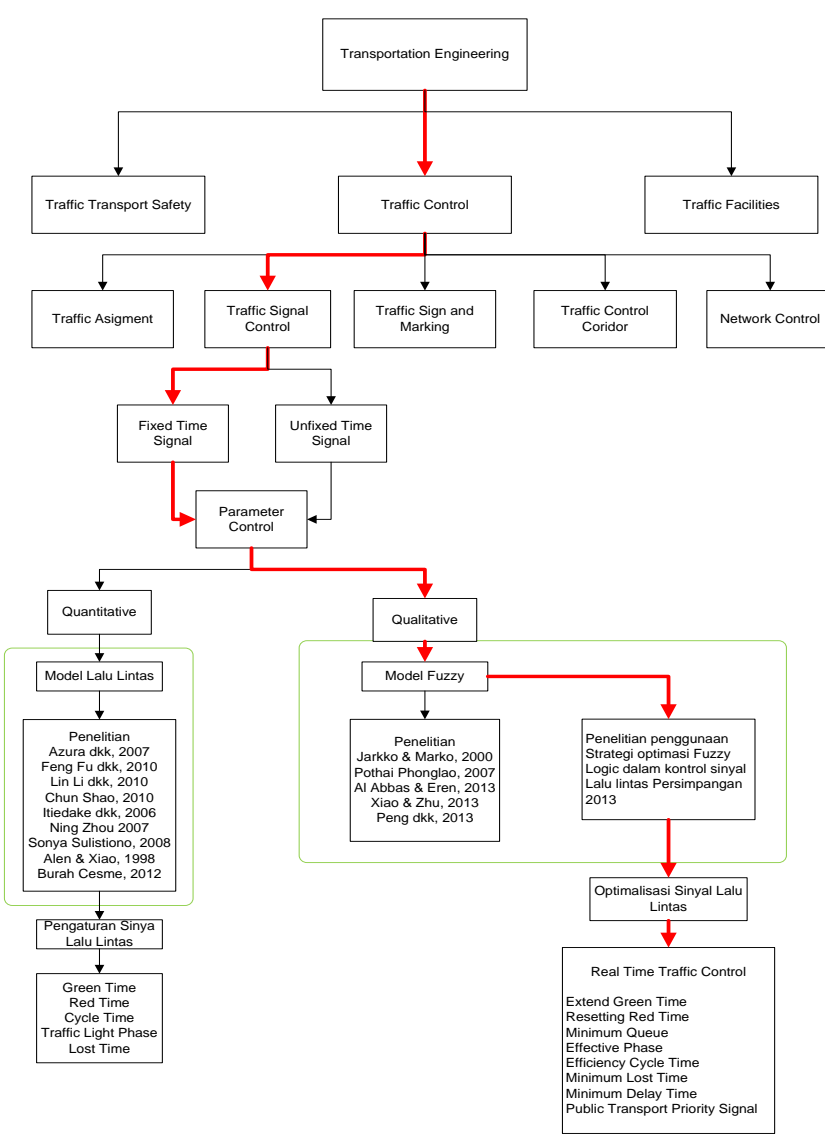

Gambar 2. Pemetaan Posisi Penelitian

\section{Kesimpulan}

Kesimpulan yang dapat diberikan dalam penelitian ini adalah sebagai berikut :

1. Model Fuzzy Logic mempunyai keunggulan dalam hal evaluasi simpang bersinyal (traffic light) berdasarkan variabel numerik dan linguistik.

2. Aspek kebaruan (state of the art) pada penelitian ini dapat menghasilkan optimasi simpang bersinyal untuk kondisi sinyal waktu tetap (fixed time signal) yang terisolasi (isolated).

3. Model Fuzzy Logic dapat dipergunakan untuk mengevaluasi kondisi persimpangan bersinyal yang ada di Indonesia, agar dapat meminimasi kemacetan dan antrian termasuk meningkatkan kapasitas simpang. 


\section{Daftar Pustaka}

Abraham Kandel, 1982, Fuzzy Techniques in Pattern Recognition, John Wiley \&Son Inc, Canada, USA.

Abraham Kandel,1986, Fuzzy Mathematical Techniques with Applications, Adison Wesley Publishing Company, Florida State University.

A.Hegyi, B.De Schutter, S.Hoogendorn, R. Babuska, H. Van Zuylen and $H$. Schuurman, 2000, A Fuzzy Decision Support System for Traffic Control Centers, Proceedings of the European Symposium on Intelligent Technique, Anchen.

Alfredo H.S.Ang, Wilson H.Tang,1976, Probability Concepts In Engineering Planning And Design,John Wiley, New York.

Alghamdi AS, Eren H, 2013, Using Fuzzy Logic to Control Vehicles Velocity in Traffic System, IFAC Proceedings Volumes.

Alper Aksac, Erkam Uzun and Tansel Ozyer, 2011, A Real Time Traffic Simulator Utilizing on Adaptive Fuzzy Inference Mechanism by Tuning Fuzzy Parameter, Springer Science Business Media.

Azura Che Soh, Muh Hamiruce Marzuki K, Rubiyah, 2007, Modelling and Optimization of a Traffic Intersection Based on Queue Theory and Markov Decision Control Methods, Proceedings of the firt Asia Internationa Conference on Modelling and Simuation.

Belohlarek, Radm Klir, George I, 2011, Concepts and Fuzzy Logic, MIT Press.

Burak Cesme, 2013, Self-Organizing Traffic Signals for Arterial Control, Dissertation, Northeastern University Boston, Massachusetts.

Chun Shao, 2009, Adaptive Control Strategy for Isolated Intersection and Traffic Network, Dissertation, University of Akron.
George J. Klir and Tina A. Folgen, 1988, Fuzzy Sets Uncertainty and Information, State University of New York Binghanton.

Hideaki Yamashita, Yo Ishizuka, Shigemichi Suzuki, 2006, Mean and Variance of Waiting time and Their Optimization for Alternating Traffic Control System, Tokyo Metropolitan University, Minami Otisawa 1-1 Hochiuji-Shi Tokyo.

Hu Hua, Gao Yunfeng, Yang Xiaoguang, 2010, Multi-Objective Optimization Method of Fixed-time Signal Control of Isolated Intersection, International Conference on Computational and Information Sciences.

Jarkko Nuttymaki, Marko Maenpaa, 2000, Fuzzy Public Transport Priority in Traffic Signal Control, Helsinki University of Technology Transportation Engineering, Finlandia.

Lin $\mathrm{Li}$, Jianmin $\mathrm{Xu}$, Sibo Huang and kai $\mathrm{Lu}$, 2010, Delay Model for signal Controlled Intersection, Journal IEEE, World Congres on Intelligent Control and Automation, Jinan, China

Moh. Nazir, Ph.D, 2013, Metoda Penelitian, Penerbit Ghalia Indonesia, Bogor.

Mohamad Alodat and Ilyas Alodat, 2013, Improve and Extension Traffic Light at Intersection, American Academic \& Scholarly Research Journal vol 5 no 3. Iran

Mojtaba Salehi, Iman Spahvand, Mohammad Yarahmadi, 2014, TLCSBFL: A Traffic Light Control System Based on Fuzzy Logic. International Journal of U- and eService and Technology, Ijunesst, Iran.

Muhammad Abbas, M. Saleem Khan, Nasir Ali and Syed Fazil, 2012, Fuzzy Logic Based Autonomous Traffic Control System, Sensors and Transducer vol 136 pp 132136, Pakistan.

Ning Zou, 2007, Queuing Models and Analyses of Traffic Control, Dissertation, University of Arizona.

PUEARI REVIEW AND THE STATE OF THE ART PADA PERSIMPANGAN BERSINYAL DENGAN MODEL 
Ofyar Z Tamin, 2008, Perencanaan, Pemodelan \& Rekayasa Transportasi, Penerbit ITB, Bandung.

Paothai Vonglao, 2007, The Solution of Traffic Signal Timing by Using Traffic Intensity Estimation and Fuzzy Logic, Dissertation, Cowan University Western Ausralia.

Peng ML, Liang XR, Dong CJ, Liu YY, 2013, Freway traffic Congestion Identification Based on Fuzzy Logic Inference, Journal Applied Mechanic and Material vol 397400 pp 2227-2230, China.

PUEERI REVIEW AND THE STATE OF THE ART PADA PERSIMPANGAN BERSINYAL DENGAN MODEL FUZZY LOGIC 